\title{
Formação de professores em Ciências da Natureza para escolas do/no campo na UFFS - Campus Erechim: perspectivas e desafios
}

\author{
Moises Marques Prsybyciem ${ }^{1}$, Almir Paulo dos Santos ${ }^{2}$, Jeronimo Sartori ${ }^{3}$ \\ ${ }^{1}$ Universidade Federal da Fronteira Sul - UFFS. Campus Erechim. Curso Interdisciplinar em Educação do \\ Campo: Ciências da Natureza. Rodovia ERS, km 135, 200. Zona Rural. Erechim - RS. Brasil. \\ moises.prsybyciem@uffs.edu.br. ${ }^{2}$ Universidade Federal da Fronteira Sul - UFFS. ${ }^{3}$ Universidade Federal da \\ Fronteira Sul - UFFS.
}

RESUMO. Este trabalho tem o objetivo de evidenciar as perspectivas e os desafios encontrados na formação inicial de professores no Curso Interdisciplinar em Educação do Campo: Ciências da Natureza - Licenciatura da Universidade Federal da Fronteira Sul, Campus Erechim, para escolas do/no campo. Essa pesquisa bibliográfica e documental é de natureza exploratória, cuja abordagem foi do tipo qualitativa. Os principais resultados evidenciam desafios e potencialidades na formação de professores para as escolas localizadas nas comunidades indígenas e nas escolas do/no campo, bem como sua articulação com o Ensino de Ciências da Natureza (Química, Física e Biologia), tais como: a identidade cultural dos sujeitos, o choque de culturas (diferentes povos do campo e diferentes especificidades), os aspectos pedagógicos relacionados à organização e ao trabalho no regime de alternância. Esses elementos apontam para um perfil de professor formado em uma Licenciatura em Educação do Campo que precisa compreender as contradições culturais, ideológicas, sociais, políticas, científicas, tecnológicas, éticas e econômicas enfrentadas pelos sujeitos que vivem do e no campo. Esses resultados mostram a necessidade de ampliação das discussões sobre Ciência e Tecnologia e suas implicações sociais, visando fortalecer a identidade e a cultura do campo que lhe é própria.

Palavras-chave: Educação do Campo, Ensino de Ciências da Natureza, Alternância, Formação de Professores. 


\title{
Teacher training in Nature Sciences for rural schools in the UFFS - Campus Erechim: perspectives and challenges
}

\begin{abstract}
This work aims to highlight the perspectives and challenges encountered in the initial training of teachers in the Interdisciplinary Course in Rural Education: Natural Sciences Bachelor of the Federal University of the Southern Frontier, Campus Erechim, for schools in the countryside. This bibliographic and documentary research is of an exploratory nature, whose approach was of the qualitative type. The main results highlight the challenges and potentialities of teacher training for schools located in indigenous communities and schools in the countryside, as well as their articulation with the Teaching of Natural Sciences (Chemistry, Physics and Biology), such as: identity Cultural diversity of the subjects, the clash of cultures (different rural people and different specificities), pedagogical aspects related to organization and work in the alternation regime. These elements point to a teacher profile graduated in a Rural Education Degree that needs to understand the cultural, ideological, social, political, scientific, technological, ethical and economic contradictions faced by subjects living in and out of the field. These results show the need to broaden the discussions on Science and Technology and its social implications, aiming to strengthen the identity and culture of the field that is its own.
\end{abstract}

Keywords: Rural Education, Natural Sciences Teaching, Alternation, Teacher Training. 


\section{Formación de profesores en Ciencias de la Naturaleza para escuelas del campo en la UFFS - Campus Erechim: perspectivas y desafíos}

RESUMEN. Este trabajo tiene el objetivo de evidenciar las perspectivas y los desafíos encontrados en la formación inicial de profesores en el Curso Interdisciplinario en Educación del Campo: Ciencias de la Naturaleza - Licenciatura de la Universidad Federal de la Frontera Sur, Campus Erechim, para escuelas del/en el campo. Esta investigación bibliográfica y documental es de naturaleza exploratoria, cuyo enfoque fue del tipo cualitativo. Los principales resultados evidencian desafíos y potencialidades en la formación de profesores para las escuelas ubicadas en las comunidades indígenas y en las escuelas del / en el campo, así como su articulación con la Enseñanza de Ciencias de la Naturaleza (Química, Física y Biología), tales como: la identidad Cultural de los sujetos, el choque de culturas (diferentes pueblos del campo y diferentes especificidades), los aspectos pedagógicos relacionados a la organización y al trabajo en el régimen de alternancia. Estos elementos apuntan a un perfil de profesor formado en una Licenciatura en Educación del Campo que necesita comprender las contradicciones culturales, ideológicas, sociales, políticas, científicas, tecnológicas, éticas y económicas enfrentadas por los sujetos que viven del y en el campo. Estos resultados muestran la necesidad de ampliar las discusiones sobre Ciencia y Tecnología y sus implicaciones sociales, con el fin de fortalecer la identidad y la cultura del campo que le es propia.

Palabras clave: Educación Rural, Enseñanza de Ciencias de la Naturaleza, Alternancia, Formación de Profesores. 


\section{Introdução}

Os cursos de Licenciatura em Educação do Campo (LEdoC) são frutos de intensas lutas dos diversos movimentos, lideranças sociais e indígenas pelo direito à Educação do Campo. O projeto de educação para o camponês possui uma pedagogia própria, construída pelos seus sujeitos. Os sujeitos do campo, tais como os indígenas, os agricultores familiares, os quilombolas, os assentados, os caiçaras, os povos das florestas, dentre outros, assim como o Movimento dos Atingidos por Barragens (MAB), o Movimento dos Trabalhadores Rurais Sem Terra (MST) e Movimento das Mulheres Camponesas (MMC), possuem o direito a uma educação pública de qualidade e que respeite as suas dinâmicas sociais e culturais, atendendo às suas necessidades e especificidades (Arroyo, Caldart \& Molina, 2004).

A história de criação da Universidade Federal da Fronteira Sul (UFFS) encontra-se diretamente ligada às lutas desses movimentos sociais da região pela construção da proposta de uma universidade pública e popular para todos. Tais compromissos foram assumidos pela UFFS em prol da superação das desigualdades sociais e regionais, especialmente quanto à população mais excluída do campo e da cidade, engajada numa luta por uma educação como direito humano, possibilitando aos sujeitos, em especial aos que foram excluídos no tempo normal do processo educativo, terem acesso a uma formação superior de qualidade, preservando a sua identidade cultural do e no campo.

Nesse contexto, a UFFS participou do Edital PRONACAMPO/2012, propondo o Curso Interdisciplinar em Educação do Campo: Ciências da Natureza - Licenciatura (CIEdoCCN-L). A principal proposta do curso é a formação de professores para atuarem no Ensino Fundamental e Médio em escolas do/no campo na área de Ciências da Natureza, priorizando a diversidade das populações do campo que ainda não tiveram oportunidade de ingressar na Educação Superior. Além disso, esse processo visava atender a uma demanda da região em relação à falta de profissionais nessa área e, talvez, contrapor o desmonte e fechamento das escolas do campo com a formação de professores capacitados e comprometidos com os sujeitos do e no campo.

O projeto de Educação do Campo sempre expressou a necessidade de formar professores capazes de compreender as contradições culturais, ideológicas, sociais, políticas, éticas e econômicas enfrentadas pelos sujeitos que vivem do e no campo. $\mathrm{O}$ projeto também atende à necessidade da 
discussão sobre os aspectos científicos e tecnológicos e, a partir daí, desenvolver práticas educativas e organizacionais que preparem esses professores para enfrentar essas contradições (Molina \& Sá, 2011). É possível identificar alguns desafios e perspectivas nos processos formativos, tanto no âmbito da Universidade, como nos espaços das alternâncias, que, trabalhados, potencializam uma maior qualidade formativa e educacional para os povos do e no campo.

Por isso, o objetivo deste trabalho é evidenciar, no processo de formação de professores, os desafios e as perspectivas no CIEdoCCN-L da UFFS, Campus Erechim, para escolas do/no campo. O intuito é fortalecer nossas práticas pedagógicas para os procedimentos de ensino e aprendizagem, com a discussão de variados aspectos, como o regime de alternância, buscando a melhoria formativa dos professores e dos estudantes na realidade do e no campo, como parcela da população nacional que, historicamente, se encontra desassistida pelas universidades públicas.

\section{Formação de professores de Ciências da Natureza para escolas do/no campo}

A formação de professores é uma das temáticas com maior ênfase nos trabalhos de pesquisa em educação em Ciências
(Maldaner, 1999; Schnetzler, 2002; Chassot, 2006; Carvalho et al., 2006; Santos \& Schnetzler, 2010; Hodson, 2014; Britto \& Silva, 2015; Bastos, 2017). Esses autores têm contribuído com as práticas pedagógicas dos professores e com a seleção de conteúdos curriculares nas escolas urbanas, nas escolas do/no campo e nas instituições de educação superior.

As discussões sobre a formação inicial e continuada de professores se caracterizam como um movimento permanente. Trata-se de movimento que se inicia já na formação escolar elementar, onde são formuladas as primeiras ideias do que é ser professor, como em suas práticas de ensino e aprendizagem, tendo presente que a formação é um processo constante. Maldaner (1999) explicita que o conceito de ser professor vai evoluindo durante a formação, e essa evolução acontece na interação com outros professores e com os diversos contextos culturais e sociais. Conforme Morin (2001), a profissão de professor é muito complexa, com muitas incertezas e com variados desafios. As principais implicações do ser professor do/no campo se referem à construção da identidade profissional, à responsabilidade político-social, como também à necessidade de compromisso com a transformação da sociedade, visando tornala mais justa, mais igualitária, inclusiva, 
humana e com menos preconceitos em relação a fatores como etnia, cor e orientação sexual.

Esses desafios exigem dos professores, em sua prática pedagógica, o rompimento com conceitos de Ciências dogmatizados, lineares, fragmentados e descontextualizados da realidade dos estudantes do/no campo, o que vai ao encontro das reflexões e da realidade do aluno. Carvalho e Gil-Pérez (1993) afirmam que cabe ao professor questionar as visões simplistas, acríticas e herdadas da ciência. Todavia, essas discussões na formação de professores para as escolas no/do campo, em específico no Ensino de Ciências da Natureza, ainda são recentes, mas, como objeto de investigação e pesquisa, devem refletir as práticas do processo de ensino e aprendizagem (Caldart, Stedile \& Daros, 2015).

O desenvolvimento científico e tecnológico e suas implicações para a sociedade precisam fazer parte das discussões na Educação do/no Campo. Assim, (re)pensar e discutir a formação inicial de professores significa compreender a importância do professor e do seu papel como agente de transformação, a partir das realidades e das especificidades dos sujeitos do/no campo e da cidade, potencializando os possíveis problemas em seus diferentes contextos (Arroyo, Caldart \& Molina, 2004).

Muitos aspectos podem ser abordados e discutidos na formação de professores de Ciências para as escolas do/no campo. Nesse sentido, um desafio complexo e relevante refere-se à necessidade de diálogo constante e simultâneo entre os processos formativos na universidade (pesquisa acadêmica/grupos de estudos) e no âmbito da educação básica (escola/comunidade) (Bastos, 2017). Conforme o Projeto Pedagógico do Curso (PPC, 2013), na LEdoC/Erechim esse processo (diálogo) ocorre na alternância. A alternância é um princípio metodológico que representa a construção de alternativas de escolarização dos povos do/no campo e se constitui no diálogo constante entre o Tempo Comunidade - TC e o Tempo Universidade - TU. Esses dois tempos são diferentes em relação a espaços, tempos, processos e produtos relacionados à formação pedagógica, mas são compreendidos de maneira integrada no processo de ensino e aprendizagem (Antunes-Rocha \& Martins, 2011).

O professor em formação, ou o professor já formado na LEdoC, tem como princípio o diálogo constante com a comunidade escolar. Desse modo, a formação busca compreender as 
contradições culturais, ideológicas, sociais, políticas, científicas, tecnológicas, éticas e econômicas enfrentadas pelos sujeitos que vivem do e no campo. Vivemos em uma sociedade cada vez mais tecnológica. Dessa forma, a formação em ciência enfrenta outro desafio, a construção do conhecimento científico e tecnológico, visando à formação para a cidadania (Santos \& Schnetzler, 2010).

Para atender a todos esses elementos em relação à formação do professor de Ciências para as escolas do/no campo, defendem-se as reflexões de Hodson (1998) em relação à necessidade de uma Alfabetização Científica Crítica (ACC) universal muito mais politizada. A ACC é um processo que busca a participação democrática de todos os atores sociais, principalmente a participação da população mais excluída socialmente (indígenas, quilombolas...) no processo de tomada de decisão responsável, politizada e efetiva em diferentes contextos (Hodson, 1998). Para Chassot (2003), uma pessoa alfabetizada cientificamente é capaz de fazer uma leitura da linguagem que está escrita na natureza, compreendendo, assim, o universo e suas relações com o ser humano, o que possibilita avaliar e criticar as suas imbricações.

Conforme Santos e Schnetzler (2010), o conhecimento científico não é uma verdade absoluta e neutra, mas, sim, influenciada pelas externalidades (política, economia, cultura), ou seja, influenciada por interesses. Assim, a ciência e a tecnologia são produzidas para atender a esses diversos interesses. Todavia, elas deveriam também, ser pensada para atender às demandas reais que a sociedade precisa enfrentar, como: a desigualdade, a fome, a violência, os problemas ambientais, dentre outros.

Quanto aos objetivos da ACC e a compreensão das contradições enfrentadas pelos povos do e no campo, esses objetivos não podem ser alcançados por meio dos tradicionais currículos e suas metodologias, focados apenas na transmissão de conteúdos (Hodson, 1998). Freire (2005) faz críticas e chama esse modelo de educação como sendo bancária, de transmissão acrítica e apolítica do conhecimento. Esse processo de ensino tradicional faz com que o aluno não identifique a relação do conteúdo abordado em sala de aula com a sua vida em sociedade.

Assim, portanto, acredita-se que uma alternativa é abordar os aspectos relacionados ao ACC e ao ativismo sociocientífico na construção de um currículo, que visa promover uma educação politizada e humana. É indispensável a um processo de ensino e 
aprendizagem que conecta o TU, como o TC, a perspectiva de buscar a transformação da realidade por meio da ação prática dos sujeitos na resolução de problemas reais, por exemplos, os relacionados ao desenvolvimento da Ciência e Tecnologia de maneira democrática, crítica, inclusiva e que aborde as dimensões ético-morais. Nesse processo, é importante a ação sociopolítica e a tomada de decisão (executar medidas e avaliar as ações) para a transformação da realidade dos sujeitos do/no campo (Hodson, 2014), focalizando uma melhor qualificação formativa no curso da LEdoC.

\section{Aspectos metodológicos}

A abordagem metodológica utilizada nesta pesquisa é qualitativa, de natureza exploratória e, do ponto de vista dos procedimentos técnicos, a pesquisa é bibliográfica e documental (Gil, 1991). Antes de tudo, trata-se de pesquisa bibliográfica porque a fundamentação teórica básica empregada deriva de livros e de artigos publicados em periódicos sobre a temática. $\mathrm{O}$ benefício dessa pesquisa relaciona-se ao fato de permitir ao investigador a cobertura de uma gama de fenômenos mais ampla em relação àquela que ele poderia pesquisar diretamente (Gil, 1991).
A pesquisa é também documental. Foram utilizados documentos institucionais: o PPC e dados do Registro Acadêmico. Conforme Gil (1991), o conceito de documento é bastante amplo, ou seja, pode ser constituído por qualquer objeto capaz de comprovar algum fato ou acontecimento - o que é o caso presente.

Os dados foram coletados do PPC (2013) e do Registro Acadêmico da UFFS (2017), dialogando com os autores que fundamentam o estudo (Antunes-Rocha \& Martins, 2011; Arroyo, Caldart \& Molina, 2004; Britto, 2011; Molina \& Sá, 2011; Ribeiro \& Ballivian, 2013; Chassot, 2006; Silva \& Prsybyciem, 2016). Dessa confrontação de dados e de ideias decorreram as reflexões e os resultados aqui produzidos para esta pesquisa.

Este estudo foi desenvolvido no Grupo de Pesquisa intitulado "Educação e Desenvolvimento Social do Campo UFFS" e isso ocorreu no ano de 2017. No primeiro momento, contextualizamos os sujeitos da LEdoC/UFFS - Campus Erechim, ou seja, dos sujeitos que se inserem no curso. No segundo momento, destacamos os processos formativos do regime de alternância e, para finalizar, expressamos as perspectivas e os desafios para a formação de professores em Ciências da Natureza para a Educação do/no Campo. 
Compreendendo o contexto e os sujeitos da LEdoC da UFFS/Erechim

A UFFS possui uma estrutura multicampi, com unidades localizadas na cidade de Chapecó/SC (sede), Erechim/RS, Cerro Largo/RS, Passo Fundo/RS, Realeza/PR e Laranjeiras do Sul/PR, com diversos cursos. O Campus de Laranjeiras do Sul e o de Erechim possuem o Curso de LEdoC, visando atender à necessidade de formação de professores do campo na área das Ciências da Natureza. Assim, o foco deste trabalho é evidenciar os processos de formação de professores no CIEdoCCN-L, no Campus de Erechim.

Esse projeto da universidade foi pensado apostando na presença das classes populares na universidade e na construção de um projeto de desenvolvimento sustentável e solidário para a região, tendo como seu eixo estruturador a agricultura familiar e camponesa, buscando a transformação da realidade, opondo-se à reprodução das desigualdades que provocaram o empobrecimento da região (PPC, 2013).

Entre os compromissos assumidos pela UFFS, que visam a superação das desigualdades sociais e regionais, está o acesso e a permanência na Educação Superior. Pensando nisso, foram criados espaços para discussões e construção de políticas diferenciadas de acesso à UFFS.
Em relação ao CIEdoCCN-L, foram construídos coletivamente, a partir de seminários e encontros com os movimentos e lideranças sociais da região, critérios que priorizassem o acesso dos sujeitos do campo à universidade (PPC, 2013). O curso, inicialmente, foi pensado para atender à necessidade de formação de professores/educadores para escolas do/no campo na área das Ciências da Natureza, para espaços escolares e não escolares da região.

Atualmente, no entanto, enfrenta-se um novo desafio, qual seja o da participação e acesso crescente no curso, a partir da segunda entrada (processo de seleção), dos povos indígenas da etnia Kaingang. O curso conta com representações, além dos indígenas, de estudantes oriundas do MST, do MAB, filhos de agricultores familiares e de integrantes da Pastoral da Juventude, contemplando uma diversidade dos povos do campo.

De acordo com os dados do Registro Acadêmico da UFFS, na turma 2013/2 primeira entrada de acadêmicos no curso foram 12 matrículas, porém nenhuma indígena. A maioria eram professores que atuavam nas escolas da região sem habilitação na área e filhos de agricultores familiares. Na turma 2014/1 ocorreu o ingresso de 18 acadêmicos, sendo 5 deles 
indígenas. $\mathrm{Na}$ turma 2014/2 foram 21 matrículas, das quais 18 foram de estudantes indígenas. Na turma 2015/1 todas as 36 matrículas foram de indígenas. Na turma 2015/2, dos 53 matriculados, 52 são indígenas e, na turma 2016/1, dos 57 matriculados, 55 deles são indígenas.

Esse processo envolve a diversidade e, ao mesmo tempo, as especificidades dos estudantes indígenas, o que nos desafia a refletir e buscar possíveis caminhos para a formação de professores em Educação do Campo: Ciências da Natureza. Outro desafio desse processo é a evasão desses acadêmicos do curso, evasão muitas vezes relacionada ao choque cultural e à dificuldade em acompanhar o curso, dificuldade em relação aos componentes curriculares, o que necessita de mais investigações e reflexões para a compreensão desse processo.

O contexto acima apresentado faz com que “... professores repensem suas práticas e adensem reflexões teóricas visando compreender a complexidade que a diversidade cultural dos educandos da etnia Kaingang impõe tanto ao corpo docente como à estrutura do Curso e da Universidade" (Silva \& Prsybyciem, 2016, p. 4). Isso nos possibilita o fortalecimento dos processos formativos do acadêmico. Conforme Candau (2011, p. 23), uma perspectiva de interculturalidade defende uma,

Educação para o reconhecimento do 'outro', para o diálogo entre os diferentes grupos sociais e culturais. Uma educação para a negociação cultural, que enfrenta os conflitos provocados pela assimetria de poder entre os diferentes grupos socioculturais nas nossas sociedades e é capaz de favorecer a construção de um projeto comum, pelo qual as diferenças sejam dialeticamente incluídas.

Assim, portanto, se faz necessário o diálogo entre as culturas e o respeito aos valores, às crenças, às dinâmicas sociais e culturais, o que "permite de maneira democrática, inclusiva e dialética, que se superem conflitos e que se garantam direitos historicamente negados aos grupos socialmente excluídos" (Silva \& Prsybyciem, 2016, p. 5). Resgatar esses valores nos possibilita compreender esses sujeitos, potencializar o processo de formação de professores e garantir seus direitos sociais.

\section{O regime de alternância e sua integração aos componentes curriculares}

A LEdoC na Universidade Federal da Fronteira Sul, Campus Erechim, considera, na matriz de seu PPC, a relação entre Universidade e Comunidade. O curso organizou-se visando garantir, no máximo, $25 \%$ da carga horária de cada componente 
curricular para o TC. O CIEdoCCN-L tem em média um total de 3.390 horas, com duração de quatro anos. O TU e o TC são tempos, espaços e processos interligados e interagindo, constantemente, para a construção e a avaliação do conhecimento científico e tecnológico de maneira dialética, envolvendo saberes populares e práticas dos sujeitos do campo. Conforme Antunes-Rocha e Martins (2011, p. 214), o TC constitui-se no diálogo com o TU no contexto da luta e para a,

Construção de possibilidades da escolarização dos povos do campo. Esses termos não podem ser compreendidos de forma separada, porém são distintos no que diz respeito ao espaço, tempo, processos e produtos relacionados à formação pedagógica. Intrinsecamente ligados às formas de morar, trabalhar e viver no campo, falam-nos de limites e possibilidades para a organização da educação escolar, mas, muito mais do que isto, anunciam outra forma de fazer a escola do campo, de avaliar, da relação com os conteúdos, das mediações pedagógicas, da relação entre quem ensina e quem aprende.

A alternância, desse modo, foi criada como estratégia e como uma necessidade pedagógica para permitir a escolarização dos sujeitos do campo, aqui em específico, na UFFS. Essa necessidade de integração entre TU e TC é essencial para o desenvolvimento da autonomia dos estudantes, por meio da pesquisa dos problemas da comunidade e possibilitando intervenções, relacionado com os aspectos culturais, filosóficos, sociais, pedagógicos, científicos, tecnológicos, organizacionais e do trabalho. Por isso, com a interação entre os saberes populares/práticas presentes nas comunidades e o conhecimento científico, a alternância tornou-se um princípio metodológico.

$\mathrm{Na}$ UFFS, Campus Erechim, conforme o PPC (2013), os TU e TC são pensados e organizados da seguinte forma: O TU como o tempo, espaço e processos em que os alunos-professores estarão na universidade, contemplando os conteúdos dos componentes curriculares do curso. Esses alunos são, muitas vezes, oriundos de diferentes comunidades/contextos (cultura, problemas, particularidades), que, ao trazerem essas questões, ampliam as discussões sobre as realidades do campo de maneira coletiva. O TC como tempo, espaço e processos em que os estudantesprofessores estarão em seu local de origem, prioritariamente, desenvolvendo o trabalho pedagógico e as atividades de pesquisa nas Escolas do/no Campo e demais espaços educativos não escolares nas comunidades.

De acordo com o PPC (2013) do curso, para possibilitar o vínculo entre esses momentos, estão previstos, em cada semestre, os componentes curriculares denominados Seminários Integradores das 
Práticas Pedagógicas. Nesses componentes são potencializados espaços para discussão, articulação e socialização dos conteúdos e aprendizagens desenvolvidas durante o processo. Ressalta-se que estão previstas atividades para o TC em todos os componentes curriculares do curso.

Silva e Prsybyciem (2016) explicitam o trabalho desenvolvido no componente curricular Seminários Integradores das Práticas Pedagógicas I, com uma turma, majoritariamente, de estudantes indígenas como significativo. Essa experiência desenvolveu-se na primeira etapa do curso, com uma turma que entrou no primeiro semestre de 2016 e tem como eixo de investigação o "Processo educativo do sujeito licenciando em educação do campo. Processo históricocultural dos sujeitos" (PPC, 2013, p. 42).

Nesse processo, foram construídos memoriais descritivos da trajetória escolar e sua respectiva reflexão crítica, em que foi possível perceber aspectos fortes na análise dos memoriais e no TC, que devem ser respeitados e levados em consideração, na prática pedagógica, para a formação de professores para a população indígena e camponesa. Esses aspectos podem ser articulados com os conhecimentos de Ciências Naturais (Química, Física e Biologia), como: a identidade cultural, a territorialidade, a língua materna, os aspectos relacionados ao choque cultural, culinária, artesanato, mitos e os saberes populares (Silva \& Prsybyciem, 2016).

O TC no CIEdoCCN-L se traduz por meio de todos os componentes curriculares e, principalmente, no componente Seminário Integrador das Práticas Pedagógicas, potencializando a prática como componente curricular, uma vez que se aproxima da escola na educação básica e interage com a comunidade. A partir disso é imprescindível considerar as mais diversas contradições sociais e culturais, nos contextos políticos, científicos, tecnológicos, econômicos, éticos e ambientais.

Esse momento - o TC - necessitaria de mais mediadores, o que vai ao encontro das experiências da alternância realizada no curso de LEdoC da Universidade Federal de Minas Gerais (UFMG), mediadores tais como o Orientador de Aprendizagem, os Guias do Tempo Comunidade e os Trabalhos do Tempo Comunidade (Antunes-Rocha \& Martins, 2011, grifo dos autores). Todavia, na conjuntura política, ideológica e econômica atual, esse processo constante para acompanhamento no TC tem ficado cada vez mais difícil, dada a escassez de recursos financeiros e humanos.

Assim, portanto, conforme concluíram Silva e Prsybyciem (2016), há 
um convite para formadores de professores, para reforçarem as práticas pedagógicas, (re)pensarem estratégias que busquem atender às necessidades e às especificidades para a formação de educadores, principalmente, para a educação básica nas aldeias e nas escolas do/no campo. Nesse sentido, cabe entender que tais sujeitos já possuem uma dinâmica social e cultural e que deve ser respeitada, mesmo com todos os desafios impostos pela conjuntura nacional.

\section{Perspectivas e desafios na formação de professores em Ciências da Natureza para as escolas do/no campo}

O Ensino de Ciências (Química, Física e Biologia) nas escolas de Educação Básica do/no Campo e escolas urbanas, bem como na Educação Superior em Cursos de Licenciatura, muitas vezes, é desenvolvido de forma linear, fragmentada e apresentando conteúdos como verdades absolutas e acabadas, ensino esse que tem a sua herança numa visão positivista de ciência (Auler \& Delizoicov, 2006). Talvez esse modelo desenvolvido nas instituições de ensino seja reflexo dessas concepções tradicionais, causando lacunas na formação inicial dos professores nessa área de conhecimento, o que pode refletir negativamente na prática pedagógica em sala de aula.
Nesse contexto, pesquisadores e professores, (Chassot, 2006; Auler, 2007; Pinheiro, Silveira e Bazzo, 2007; Santos e Schnetzler, 2010), fazem críticas a essa visão e defendem um Ensino de Ciências contextualizado e interdisciplinar, articulado com os contextos científicos, econômicos, tecnológicos, éticos, ambientais, sociais, culturais e políticos.

$\mathrm{Na}$ LEdoC, na área de Ciência da Natureza começou a ser discutida a formação de professores de maneira coletiva, a partir da primeira turma de LEdoC do Instituto de Educação Josué de Castro, em parceria com o Iterra/UnB, concluída em 2011. Essas discussões possibilitaram a percepção da pouca atenção dada às Ciências da Natureza na Educação do Campo, chegando ao entendimento de que é preciso ouvir e dialogar mais com os professores dessa área (Caldart, Stedile \& Daros, 2015).

A formação de professores em Ciências da Natureza para a educação do/no campo na UFFS - Campus Erechim explicita que é essencial resgatar, tanto a identidade cultural, quanto a valorização dos sujeitos em seu espaço social. Para isso, se faz necessário articular as práticas pedagógicas direcionadas à sua cultura e às suas vivências no desenvolvimento do conhecimento científico e tecnológico interligado aos saberes e às práticas 
populares. Para Arroyo, Caldart e Molina (2004), a Educação do/no Campo não expressa somente o seu lugar, mas seus sujeitos, no sentido de valorização dos conhecimentos de suas práticas sociais camponesas, enfatizando o campo como lugar em construção e desenvolvimento sustentável de seu espaço.

Todavia, esse direito à educação ficou esquecido e foi negado por muito tempo em políticas públicas sociais e educacionais para a população campesina (Arroyo, Caldart \& Molina, 2004). A educação é um direito humano e deve ser garantido a todos os seres humanos, independentemente de qualquer condição pessoal ou social (cor de pele, orientação sexual, classe social e etnia). Ela pode ocorrer no âmbito da família, no trabalho, nos sistemas escolares e na comunidade.

Os sistemas escolares fazem parte desse processo, caracterizado como organização legal em regime de colaboração com os outros sistemas (municipais, estaduais e federal). São, contudo, espaços de intencionalidades conscientes ou não. Com a educação escolar são acessados, por exemplo, os bens culturais, as leis e as normas, a ciência, a tecnologia e a participação consciente e responsável no desenvolvimento político (Haddad, 2012).
$\mathrm{O}$ respeito à identidade e aos sujeitos que ali se encontram imbricados (povos do campo) possibilita o cultivo de um conjunto de princípios que podem orientar as práticas educativas, favorecendo a ligação entre a formação do licenciado e a formação para uma postura crítica na vida e na comunidade, onde se encontra inserido. $\mathrm{O}$ processo de ensino e aprendizagem deveria permitir $\mathrm{o}$ enriquecimento do espaço cultural e social dos sujeitos do e no campo, sem perder sua identidade, potencializando seu espaço e desenvolvendo, a partir de sua realidade, a construção dos conhecimentos científicos, tão necessários nos espaços de formação das salas de aula da escola básica e da também da universidade.

Os sujeitos do e no campo, quando inseridos nos espaços formativos, são portadores de uma diversidade de saberes e de práticas diárias: esses conhecimentos podem ser o ponto de partida para a construção de conceitos no Ensino de Ciências. A despeito disso, é essencial superar aquela visão tradicionalista e estereotipada de que os sujeitos que vivem no campo são atrasados, arcaicos e desqualificados em relação aos que vivem na realidade urbana (Arroyo, Caldart \& Molina, 2004). É preciso reconstruir um novo olhar acerca do espaço rural e dos sujeitos que nele vivem, superando a 
ideologia mercadológica e do agronegócio.

Essa visão tem historicamente construído uma retrógrada identidade cultural do e no campo, o que faz do campo um lugar que, por assim dizer, passa despercebido do meio urbano.

Assim, para que ocorra construção dos conhecimentos científicos e tecnológicos, é preciso resgatar a maneira de pensar dos sujeitos do campo. Trata-se de uma tentativa de superar as fragilidades que foram impostas aos sujeitos por um modelo de sociedade que constantemente evidencia um único modelo cultural - o modelo capitalista (Fernandes, Cerioli \& Caldart, 2011). O ponto de partida seria demonstrar que os sujeitos que vivem no campo trazem uma cultura e identidade própria de valorização das características do campo - uma cultura e identidade que precisam ser respeitadas. Importante é utilizar os recursos do local de convívio do estudante, pois são experiências ricas e potencializam tanto o processo de ensino e aprendizagem, quanto o avanço no conhecimento científico (Chassot, 2006).

É nessa ótica que entendemos que a valorização da cultura dos povos do campo traz, nos processos formativos, um sentimento de pertença ao lugar e também ao grupo social. É importante formar uma identidade social e cultural, de maneira a potencializar no educando o entendimento de si como sujeito do campo e o modo como se pode transformar esse entendimento por meio da organização e do trabalho.

Quando os povos do e no campo começam a agir como integrantes de seu grupo social, então reconhecem a sua própria identidade, potencializam as possibilidades de transformação da realidade e modificam a visão fragmentada imposta pelo sistema capitalista. Os sujeitos, quando se reconhecem, então se posicionam diante das várias transformações e descobrem nas vivências sociais um sentimento que viabiliza a defesa de seus objetivos e ideais, recriando maneiras de convivência sem distanciar-se de sua identidade cultural.

Esses sujeitos do e no campo, a partir de seus posicionamentos definidos, formulam políticas públicas que atendem aos educandos camponeses para que possam também usufruir de uma educação de qualidade. Caldart (2004) explicita que a luta por políticas públicas no e do campo é a única maneira de universalizar o acesso de todo o povo a uma educação de qualidade. É ao educar na luta que se garantem os direitos, a preservação da identidade e da cultura, o apreço ao lugar onde se vive, a participação ativa é conquistada, enquanto direito de todos os povos do e no campo. 
Respeitar a identidade cultural dos sujeitos do campo é revelar a diversidade na organização e na produção de saberes, de conhecimentos, de valores e de singularidades culturais. Tais questões devem estar presentes durante os processos formativos, respeitadas e consideradas nas propostas pedagógicas e curriculares, dando significado e potencializando os sujeitos a apropriarem-se dos conhecimentos produzidos pela humanidade. Desse modo, os sujeitos do e no campo reconstroem a sua identidade, conjuntamente com sua realidade e os conhecimentos científicos, na formação do licenciado e presente nas práticas pedagógicas.

Reconhecer, valorizar e legitimar o projeto de Educação do Campo e sua diversidade cultural como processo de construção das diferenças e dos saberes dos sujeitos é um processo inerente à produção cultural, política, econômica e de gênero. Precisa ser assumida nas práticas pedagógicas dos componentes na UFFS e nas práticas de alternância enquanto horizonte fundamental de pensar e de construir uma educação do e no campo que possibilite ao sujeito do campo a qualidade da educação, com respeito à sua identidade e cultura. Ser sujeito de si e da própria Educação do Campo é um desafio para a pretensa formação cidadã.
O regime de alternância que entrelaça TU e TC contempla, entre os seus princípios metodológicos, o do diálogo, que pode estreitar a relação entre os sujeitos e entre os saberes populares/práticas presentes nas comunidades e o conhecimento científico. Com base nisso, mesmo com todas as dificuldades e os desafios impostos pela atual conjuntura política e econômica, o TC apresenta uma outra forma de fazer a escola do campo, de avaliação, da relação da comunidade com os conteúdos, das mediações pedagógicas, das relações da ciência e tecnologia com o trabalho, dos princípios organizacionais e da relação entre quem ensina e quem aprende. Entende-se, portanto, que o TC é um potencializador da Prática como Componente Curricular. O parecer CNE 15/2005 determina que:

A prática como componente curricular é o conjunto de atividades formativas que proporcionam experiências de aplicação de conhecimentos ou de desenvolvimento de procedimentos próprios ao exercício da docência. Por meio destas atividades, são colocados em uso, no âmbito do ensino, os conhecimentos, as competências e as habilidades adquiridas nas diversas atividades formativas que compõem o currículo do curso (Brasil, 2005, p. 3).

Dessa forma, verifica-se que a prática, ao ser tomada como componente 
curricular, deve estar presente em todo o curso, em todos os componentes, articulando os tempos, espaços e processos e não apenas no período de estágio curricular obrigatório. Essa articulação entre o TC e TU, ao mesmo tempo em que se constitui em um desafio, também pode ser entendida como uma potencialidade para uma Educação do Campo contextualizada e articulada com a realidade das comunidades, dos sujeitos e das escolas, podendo ser, talvez, uma ferramenta para diminuir a evasão nos cursos de LEdoC.

Pensando no contexto e nos sujeitos da LEdoC da UFFS do Campus Erechim e na necessidade de formar professores capazes de compreenderem as contradições enfrentadas pelos sujeitos que vivem no campo, reforça-se, aqui, a importância da articulação e discussão sobre os aspectos científicos e tecnológicos com a identidade cultural dos sujeitos, respeitando os diferentes povos do campo e as suas diferentes especificidades, assim como os aspectos pedagógicos relacionados à organização e ao trabalho no regime de alternância.

O TC é fundamental para a compreensão dos problemas e dos desafios enfrentados pelos sujeitos do campo e da sua comunidade, bem como para identificar de maneira coletiva as diversas perspectivas na formação de professores em Ciências da Natureza. Neste momento acentua-se a percepção da identidade cultural e social dos sujeitos, por exemplo, a culinária, os costumes, os mitos, o artesanato e os saberes populares, que podem ser um ponto de partida para a abordagem dos conceitos científicos e tecnológicos e suas implicações para a sociedade (comunidade).

Assim, a intensa relação entre as plantas medicinais, o artesanato, os costumes e as crenças, a culinária, a produção e a conservação de alimentos, dentre outros, com a realidade encontrada pelos/as acadêmicos/as da LEdoC em suas comunidades, na maioria indígenas, instigou os professores do CIEdoCCN-L a buscarem estratégias, especificamente no Ensino de Ciências, para a abordagem dos conceitos científicos, fazendo da sala de aula um espaço para os sujeitos refletirem e construírem novas práticas científicas em suas comunidades, bem como potencializando novas experiências e novos saberes.

Os conhecimentos relacionados às plantas medicinais na cultura indígena (saber sensível dos Kujã), mas também dos demais povos do campo, podem ser explorados na Química, na Biologia e na Física, de maneira interdisciplinar, como: a importância das plantas, seus nomes, suas 
indicações terapêuticas, como preparar remédios e como tomar esses preparados (Ribeiro \& Ballivian, 2013), as contraindicações, as propriedades químicas, biológicas e físicas, as características biológicas das plantas, as relações da ciência e da tecnologia na produção de medicamentos e os interesses das empresas farmacêuticas nesses saberes. Esses são conhecimentos subjacentes nas práticas pedagógicas na universidade. Destaca-se a importância de esses aspectos serem inter-relacionados, pois eles potencializam a ampliação da construção de conhecimentos nos espaços da universidade e na comunidade.

$\mathrm{Na}$ culinária podem ser explorados os itens básicos da alimentação tradicional, tais como os nomes, a importância, o período de produção, os produtos livres de venenos, a preparação e os hábitos alimentares saudáveis (Ribeiro \& Ballivian, 2013). Ainda cabe tratar da segurança alimentar, da fome, do lixo produzido, das embalagens, dos fast foods e das relações de poder das empresas alimentícias e a influência da mídia.

As articulações midiáticas com as empresas capitalistas são intensas e atuam diretamente nos espaços da comunidade mediante a ação da indústria televisiva demonstrando, de modo ilusório, o consumo de alimentos industrializados, e então essa culinária artificial causando a perda cultural de alimentos tradicionais e culturais que historicamente foram se construindo no interior das comunidades. O espaço da sala de aula possibilita a compreensão dessa indústria cultural e o consumo capitalista, potencializando um retorno a hábitos alimentares, originários das relações culturais e da natureza, fundamentais para o desenvolvimento saudável da comunidade.

Os tipos de produção de alimentos (plantio e colheita), manejo de adubação verde, as sementes tradicionais $\mathrm{e}$ as técnicas de conservação (Ribeiro \& Ballivian, 2013), os problemas ambientais, a agroecologia, a relação da alimentação e a saúde, a chamada "revolução verde" e as relações com ciência e tecnologia, os interesse econômicos e políticos na produção de alimentos, todos são exemplos de aspectos que podem ser explorados nos processos pedagógicos integrados com a organização e o trabalho, discutindo a Química, a Física e a Biologia, respeitando a identidade cultural, as especificidades e, ao mesmo tempo, valorizando a diversidade dos sujeitos.

Os desafios na formação de professores em Ciências da Natureza para as escolas do/no campo são múltiplos e constantes. O Programa Nacional de Educação do Campo (PRONACAMPO), 
por exemplo, de que a UFFS participou em relação ao edital de 2012, visava à implementação de políticas de Educação do Campo e Indígena, tendo em vista à ampliação do acesso e da permanência e qualificação da educação superior na formação inicial e na formação continuada de professores e de outras diversas ações em todas as etapas de ensino. Esse programa foi importante para tentar diminuir as desigualdades de acesso e de permanência na educação superior. Foram mais de quarenta (40) instituições de educação superior (Federais e Estaduais) que implantaram cursos de LEdoC em diversas áreas do conhecimento.

Todavia, com os desafios impostos pela atual conjuntura política e econômica, bem como com as questões ideológicas, há uma enorme dificuldade da maioria das instituições em manter em pleno funcionamento os cursos de Educação do Campo. Diversos cortes de recursos têm acontecido tornando difícil a manutenção de condições mínimas, como o transporte para o TC e a realização de estágios, fundamentais em qualquer curso de licenciatura.

Como já mencionado, o TC apresenta uma maneira diferenciada de fazer a Educação do Campo, de avaliação, da relação da comunidade com a universidade, das mediações pedagógicas, das inter-relações de ciência e tecnologia com o trabalho e dos princípios organizacionais e da relação entre professores e estudantes. O TC, quando bem articulado com a comunidade, pode contribuir para superar outro desafio enfrentado no curso, a evasão escolar, assunto que precisa de mais discussões e reflexões nesse processo.

Outro desafio enfrentado pelos sujeitos durante a realização do curso é a dificuldade em acompanhar os componentes curriculares específicos em Química, em Física e em Biologia. Talvez essa dificuldade ocorra pela caminhada na educação básica, onde essas disciplinas, muitas vezes, eram ministradas por professores sem formação específica na área, bem como pela falta de relação dos conteúdos com os saberes e as práticas existentes na comunidade. Por isso, buscase a articulação de maneira interdisciplinar em todos os componentes e em todas as fases do curso no TC e no TU, relacionado com a dinâmica cultural e social dos sujeitos.

Entende-se, portanto, que o TC com o TU constituem-se em processo de formação de bases sólidas, pensado de maneira coletiva pelos sujeitos do e no campo, pela comunidade e pela universidade. Cabe destacar que temos ainda muito em fazer, mas percebemos que 
estamos num caminho mais sensato e eficiente no desenvolvimento das práticas pedagógicas. A certeza que nos potencializa é o TC imbricado/articulado ao TU.

Tanto assim é que os conhecimentos construídos no contexto da comunidade do e no campo, bem como os elementos científicos abordados nas práticas pedagógicas, enriquecem a formação de estudantes e de professores. As pesquisas, a extensão e o ensino universitários são construídos pensando nos TC, com o TU explicitado nos documentos, fortalecendo a qualidade na educação, como na produção de novos saberes e conhecimentos.

\section{Considerações finais}

Os desafios encontrados na formação inicial de professores em Educação do Campo na área de Ciência da Natureza são constantes, tais como: necessidade de investimentos financeiros básicos para atender ao desenvolvimento do TC e do estágio, a evasão e a dificuldade dos acadêmicos em acompanhar os componentes curriculares específicos (em química, em física e em biologia) do CIEdoCCN-L. Para minimizar esses desafios, a articulação entre o TU e TC tornou-se uma alternativa, porém ainda se fazem necessárias mais discussões e reflexões. A interdisciplinaridade que acontece no TU e no TC pode ajudar professores e estudantes a superar essas dificuldades no processo de ensino e aprendizagem.

Esse processo nos instiga a promover discussões e reflexões, buscando novos caminhos e perspectivas, tais como políticas sociais e educacionais, a necessidade de compreensão da identidade social e cultural dos sujeitos em formação, a valorização da diversidade e dos interesses coletivos frente à lógica do sistema capitalista.

Assim, percebe-se que a alternância com o TC em diálogo com o TU -, se torna um potencializador da prática como componente curricular, haja vista que procura aproximar todos os componentes curriculares do curso, a realidade das comunidades, da escola e dos seus sujeitos. Essa conexão com a comunidade acentua a percepção dos problemas e das possibilidades. Tais elementos podem ser os pontos de partida para a identificação de temas para a articulação com as Ciências da Natureza, permitindo compreender as contradições e os problemas complexos de ordem ambiental, social, tecnológica, científica, econômica, politica, ética e ideológica.

Assim, portanto, o Ensino de Ciências pode ser abordado por meio de 
temas que emergem da realidade e das discussões coletivas com os diferentes sujeitos das comunidades. A relação e a interação dos saberes populares/práticas dos sujeitos e os conhecimentos científicos e tecnológicos, de forma dialética, podem instrumentalizar os povos do campo para a luta por igualdade e por justiça social. A compreensão da realidade e das mazelas que tecem a ordem social pode motivar a luta por questões de interesse coletivo e pela formação para a cidadania, contrapondo-se, assim, à ordem capitalista, na qual os valores econômicos e políticos se impõem aos demais valores, aprofundando a desigualdade e a exclusão.

Os saberes que emergem das comunidades do e no campo são os potencializadores das práticas pedagógicas e formativas, tanto do discente como do docente. $\mathrm{O}$ TC aliado ao TU nos proporciona meios para encontrar uma nova maneira de construir saberes/conhecimentos. Há um sentimento de pertencimento dos sujeitos nos processos de ensino e aprendizagem. O conhecimento científico não fica descontextualizado, mas integrado à realidade do estudante. $\mathrm{O}$ professor também aprende em todos os processos de ensino, tanto nas experiências científicas nos laboratórios, como em sala de aula e no TC. O TC, articulado com o conhecimento científico do TU, nos ensina a sermos sujeitos produtores de conhecimentos, possibilitando ter atitude ativa no ato de construir, especialmente, na formação do Licenciado, para que assuma o compromisso do que é ser professor.

\section{Referências}

Auler, D. (2007). Enfoque CiênciaTecnologia-Sociedade: pressupostos para o contexto brasileiro. Revista Ciência $e$ ensino, 1. Recuperado de: http://ltcead.nutes.ufrj.br/constructore/objetos/auler .pdf

Auler, D., \& Delizoicov, D. (2006). Ciência-Tecnologia-Sociedade: relações estabelecidas por professores de ciências. Revista Electrónica de Enseñanza de las Ciencias, 5(2), 337-355. Recuperado de: http://reec.uvigo.es/volumenes/volumen5/ ART8_Vol5_N2.pdf

Antunes-Rocha, M. I., \& Martins, M. F. A (2011). Diálogo entre teoria e prática na Educação do Campo: Tempo Escola/Tempo Comunidade e alternância como princípio metodológico para organização dos tempos e espaços no curso de Licenciatura em Educação do Campo. In Molina, M. C., \& Sá, L. M. (Orgs). Licenciaturas em educação do campo: registros e reflexões a partir das experiências - piloto (UFMG; UnB; UFBA e UFS (pp. 213-228). Belo Horizonte, MG: Autêntica Editora.

Arroyo, M. G., Caldart, R. S., \& Molina, M. C. (2004). Por uma educação do campo. Petrópolis, RJ: Vozes Editora.

Bastos, F. (2017). A pesquisa em educação em ciências e a formação de professores. Ciência \& Educação, 23(2), 299-302. Recuperado 
http://www.scielo.br/pdf/ciedu/v23n2/1516 -7313-ciedu-23-02-0299.pdf

Brasil. (2005). Ministério da Educação e Cultura. Conselho Nacional de Educação. Parecer CNE/CES $n^{\circ} 15,02$ de fevereiro de 2005. Solicitação de esclarecimento sobre as Resoluções CNE/CP $n^{\circ}$ 1/2002, que institui Diretrizes Curriculares Nacionais para a Formação de Professores da Educação Básica, em nível superior, curso de licenciatura, de graduação plena, e 2/2002, que institui a duração e a carga horária dos cursos de licenciatura, de graduação plena, de Formação de Professores da Educação Básica, em nível superior. Brasília, DF.

Britto, N. S. (2011). Formação de professores e professoras em Educação do Campo por área de conhecimento Ciências da Natureza e Matemática. In Molina, M. C., \& Sá, L. M. (Orgs.). Licenciaturas em educação do campo: registros e reflexões a partir das experiências - piloto (UFMG; UnB; UFBA $e$ UFS) (pp. 165-178). Belo Horizonte, MG: Editora Autêntica.

Britto, N. S., \& Silva, T. G. R. (2015). Educação do Campo: formação em ciências da natureza e o estudo da realidade. Educ. Real, 40(3), 763-784. Recuperado http://ref.scielo.org/29hhhp

Caldart, R. S. (2004). Por uma educação do campo: traços de uma identidade em construção. In Arroyo M., Caldart, R., \& Molina. M. (Orgs). Por uma Educação do Campo (pp. 147-160). Petrópolis, RJ: Editora Vozes.

Caldart, R. S., Stedile, M. E., \& Daros, D. (Orgs.). (2015). Caminhos para transformação da escola 2: agricultura camponesa, educação politécnica e escolas do campo. São Paulo, SP: Expressão Popular Editora.
Candau, V. (2011). Multiculturalismo e educação: desafios para a prática pedagógica. In Moreira, A. F., \& Candau, V. (Orgs.). M. Multiculturalismo: diferenças culturais e práticas pedagógicas. Petrópolis, RJ: Vozes.

Carvalho, A. M. P., \& Gil-Pérez, D. (1993). Formação de professores de Ciências: tendências e inovações. Coleção questões da nossa época, 28. São Paulo, SP: Cortez Editora.

Carvalho, A. M. P., et al. (2006). Ensino de Ciências: unindo a pesquisa e a prática. São Paulo, SP: Editora Pioneira Thomson Learning.

Chassot, A. (2003). Alfabetização científica: uma possibilidade para a inclusão social. Revista Brasileira de Educação, 22, 89-100. Recuperado de: http://dx.doi.org/10.1590/S141324782003000100009.

Chassot, A. (2006). Alfabetização científica: questões e desafios para a educação. Ijuí: Ed. Editora Unijuí.

Fernandes, B. M., Cerioli, P. R., \& Caldart, R. S. (2011). Primeira Conferência Nacional. "Por uma Educação Básica do Campo". In Arroyo, M. G., Caldart, R. S., \& Molina, M. C. (Orgs.) Por uma educação do campo (pp. 19-63). Petrópolis, RJ: Vozes Editora.

Freire, P. (2005). Pedagogia do Oprimido. Rio de Janeiro, RJ: Editora Paz e Terra.

Gil, A. C. (1991). Como elaborar projetos de pesquisa. São Paulo, SP: Editora Atlas.

Haddad, S. (2012). Direito à Educação. In Caldart, R. S., Perreira, I. B., Alentejano, P., \& Frigotto, G. (Orgs.). Dicionário da Educação do Campo (pp. 215-222). Rio de Janeiro, RJ: Expressão Popular Editora. 
Hodson, D. (1998). Learning and Teaching Science: Approach Personalized a Towards. Buckingham: Open University Press.

Hodson, D. (2014). Becoming Part of the Solution: Learning Activism, Learning through Activism, Learning from Activism. In Bencze, L., \& Alsop, S. (Eds). Activist Science and Technology Education (pp. 67-98). Dordrecht: Springer Press.

Maldaner, O. A. (1999). A pesquisa como perspectiva de formação continuada do professor de química. Revista Química Nova, 22(2), 289-292: Recuperado de: http://quimicanova.sbq.org.br/imagebank/p df/Vol22No2_289_v22_n2_20\%2822\%29. $\underline{\mathrm{pdf}}$

Molina, M. C., \& Sá, L. M. (Orgs.). (2011). Licenciaturas em educação do campo: registros e reflexões a partir das experiências - piloto (UFMG; UnB; UFBA e UFS). Belo Horizonte, MG: Autêntica Editora.

Morin, E. (2001). Os sete saberes necessários à educação do futuro. São Paulo, SP: Editora Cortez.

Pinheiro, N. A. M., Silveira, R. M. C. F., \& Bazzo, W. A. (2007). Ciência, Tecnologia e Sociedade: a relevância do enfoque CTS para o contexto do ensino médio. Ciência \& Educação, 13(1), 71-84. Recuperado de: http://www.scielo.br/scielo.php?script=sci arttext\&pid=S151673132007000100005 $\& \operatorname{lng}=$ en \&nrm=iso\&tlng=pt.

Projeto Pedagógico do Curso (PPC) Interdisciplinar em Educação do Campo (Ciências da Natureza) - Licenciatura do Campus Erechim. (2013). Recuperado de: https://www.uffs.edu.br/atosnormativos/ppc/ccieccner/2016-0001

Ribeiro, L. E. S., \& Ballivian, J. M. P. (2013). Reflexões sobre o ensino da disciplina de Ciências no currículo de escolas Kaingang. In Benvenuti, J., Bergamaschi, M.A., \& Marques, T. B. I.; (Orgs.). Educação Indígena sob o ponto de vista de seus Protagonistas (pp. 209-216). Porto Alegre, RS: Evangraf.

Santos, W. L. P., \& Schnetzler, R. P. (2010). Educação em Química: compromisso com a cidadania. Ijuí: Unijuí Editora.

Silva, D., \& Prsybyciem, M. M. (2016). Formação de Educadores Indígenas: Identidade, Autonomia e Práticas Pedagógicas. In Anais Seminário Regional Diálogos Interculturais, Currículo $e$ Educação de Fronteira Étnico-Racial. Dourados. Recuperado de: https://drive.google.com/file/d/0B7AxcCG ceUUEa2twVzlESElKa2M/view

Schnetzler, R. P. (2002). Concepções e alertas sobre formação continuada de professores de química. Química Nova na Escola, 16, 15-20. Recuperado de: http://qnesc.sbq.org.br/online/qnesc16/v16 A05.pdf

Recebido em: 27/07/2017

Aprovado em: 01/08/2017

Publicado em: 13/12/2017

Como citar este artigo / How to cite this article / Como citar este artículo:

APA:

Prsybyciem, M. M., Santos, A. P., \& Sartori, J. (2017). Formação de professores em Ciências da Natureza para escolas do/no campo na UFFS - campus Erechim: perspectivas e desafios. Rev. Bras. Educ. Camp., 2(3), 941-964. DOI: http://dx.doi.org/10.20873/uft.2525-

$\underline{4863.2017 \mathrm{v} 2 \mathrm{n} 3 \mathrm{p} 941}$

ABNT:

PRSYBYCIEM, M. M.; SANTOS, A. P.; SARTORI, J. Formação de professores em Ciências da Natureza para escolas do/no campo na UFFS - campus Erechim: perspectivas e desafios. Rev. Bras. Educ. Camp., Tocantinópolis, v. 2, n. 3, p. 941-964, 2017. DOI: $\quad$ http://dx.doi.org/10.20873/uft.25254863.2017v2n3p941 
Prsybyciem, M. M., Santos, A. P., \& Sartori, J. (2017). Formação de professores em Ciências da Natureza para escolas do/no campo na UFFS - Campus Erechim: perspectivas e desafios...

\section{ORCID}

Moises Marques Prsybyciem

Dhttp://orcid.org/0000-0001-8220-7416

Almir Paulo dos Santos

http://orcid.org/0000-0002-9283-3178

Jeronimo Sartori

http://orcid.org/0000-0002-5753-8894 